\title{
Producción y eVAlUaCión INMUNOQUímica de eXtRactos ALERGÉNICOS DEL ÁCARO DEL POLVO DOMÉSTICO Blomia tropicalis (ACARI: ECHYMYOPODIDAE)
}

\author{
Luis Acuña-Cantillo', Dary Luz Mendoza-Meza², Gloria Garavito', \\ Ana Sofía Moreno-Woo' y Eduardo Egea-Bermejo ${ }^{1 *}$ \\ ${ }^{1}$ Grupo de investigación en Inmunología y Biología molecular. Departamento de Medicina, \\ División Ciencias de la Salud, Universidad del Norte, Kilómetro 5 Antigua vía a Puerto Colombia, \\ 081007, Barranquilla - Atlántico, Colombia. ${ }^{2}$ Grupo de investigación en Productos Naturales y \\ Bioquímica de Macromoléculas. Programa de Química, Facultad de Ciencias Básicas, Universidad \\ del Atlántico, Barranquilla - Atlántico, Colombia. Correo electrónico:*eegea@uninorte.edu.co
}

\begin{abstract}
Resumen
Los alérgenos de Blomia tropicalis son un factor de riesgo para el desarrollo de alergias en países tropicales. Los extractos alergénicos son reactantes valiosos para el diagnóstico de la hipersensibilidad alérgica a los ácaros y su control biológico. El objetivo fue evaluar las propiedades inmunoquímicas de extractos de B. tropicalis producidos desde cultivos in vitro. Este trabajo no tuvo como propósito producir extractos de aplicación clínica. Los ejemplares de B. tropicalis se establecieron a partir de ácaros aislados del polvo doméstico en la ciudad de Barranquilla, Colombia. Los ácaros libres de medio de cultivo se usaron para la obtención de los extractos. El rendimiento de la extracción se determinó mediante ensayo Bradford y el perfil electroforético por SDS-PAGE. La presencia de enzimas hidrolasas se determinó por Api® Zym y la inmunogenicidad se evaluó mediante Western blot donde se identificaron proteínas de unión a IgE sérica. La producción máxima de ácaros en los cultivos fue de $0,9 \mathrm{~g} / 300 \mathrm{~g}$ medio. El rendimiento de extracción de proteínas fue de $3,61 \%( \pm 0,42)$. Todos los extractos presentaron actividad enzimática tripsina, alfa-amilasa y quimotripsina. Western blot confirmó la presencia de proteínas de unión a IgE sérica. Presentamos un método sencillo para obtener extractos del ácaro B. tropicalis con actividad enzimática y alergénica.
\end{abstract}

Palabras Clave: ácaros del polvo, extractos alergénicos, cultivos, actividad enzimática, proteínas de unión a IgE.

\section{Production and immunochemical evaluation of allergenic extracts of the house dust mite Blomia tropicalis (Acari: Echymyopodidae)}

\begin{abstract}
Blomia tropicalis allergens are a risk factor for allergy in tropical countries. The allergenic extracts are valuable reactants for house dust mite hypersensitivity diagnostic and its biological control. The objective was to evaluate the immunochemical properties of $B$. tropicalis extracts produced from in vitro cultures. This work was not intended to produce extracts for clinical application B. tropicalis specimens were established from mites isolated from domestic dust in Barranquilla, Colombia. The mites free of culture medium were used to obtain the extracts. The yield of extraction was determined by Bradford assay and the electrophoretic profile by SDS-PAGE. The presence of hydrolase enzymes was determined by Apiß Zym and the immunogenicity was evaluated by Western blot where serum IgE binding proteins were identified. The maximum production of mites in the cultures was $0.9 \mathrm{~g} / 300$ $\mathrm{g}$ of medium. The yield of protein extraction was $3.61 \%( \pm 0.42)$. All the extracts showed enzymatic activity for trypsin, alpha-amylase, chymotrypsin associated. The Western blot confirmed the serum IgE binding proteins. We showed a simple and fast method to obtain B. tropicalis extracts with enzymatic and allergenic activity.
\end{abstract}

Key Words: house dust mites, allergenic extracts, cultures, enzyme activity, IgE binding proteins.

Nota: Artículo recibido el 15 de febrero de 2018 y aceptado el 22 de junio de 2018. 


\section{INTRODUCCIÓN}

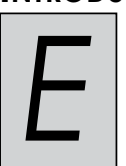

1 ácaro del polvo doméstico Blomia tropicalis se distribuye principalmente en el cinturón del trópico y algunas ciudades costeras de Europa y Estados Unidos de Norteamérica (Collof, 2009), presenta alérgenos con una amplia diversidad de actividades biológicas que incluyen proteínas con: actividad enzimática (Blo t 1, Blo t 3, Blot 4, Blo t 6, Blo t 8, Blo t 9, Blo t 15, Blo t 18, Blo t 20), pertenecientes a la familia de proteínas Niemann-Pick tipo C2, NPC2 (Blot2), estructurales (Blo t 10, Blo t 11), de unión a quitinas (Blo t 12), de unión a lípidos (Blot 13), con actividad antimicrobiana (Blo $\mathrm{t} 19)$, con capacidad para aumentar la permeabilidad bacteriana (Blo t 7), apolipoforinas (Blo t 14) y otras cuya función es aún desconocida (Blo t 5, Blo t 21) (Chua et al., 2007, http://www. allergome.org), siendo estos alérgenos considerados factor de riesgo para el desarrollo de asma y alergias principalmente en poblaciones expuestas (Caraballo, 1999).

B. tropicalis es una de las principales fuentes de aero-alérgenos en el polvo doméstico de ciudades del caribe Colombiano. Estudios previos han informado prevalencias para esta especie de $46 \%$ en Santa Marta (Meza, Mendoza \& Mercado, 2008), 92\% en Barranquilla (Acuña-Cantillo, Moreno, Garavito, Egea \& Mendoza-Meza, 2015) 96\% en Cartagena (Fernández-Caldas, Puerta, Mercado, Lockey \& Caraballo, 1993), lo cual podría explicar las altas prevalencias de las enfermedades alérgicas observadas en esta población. Estudios realizados en la ciudad de Cartagena, demuestran que los pacientes alérgicos sensibilizados a $B$. tropicalis están expuestos a una carga alergénica elevada durante todo el año (Mercado, Puerta \& Caraballo, 1996), detectándose niveles altos de anticuerpos IgE anti-B. tropicalis cercanos a $85,5 \%$ mediante la prueba RAST (acrónimo del inglés Radio Allergo Sorbent Test), en el suero de los asmáticos residentes en esta ciudad (Puerta, Fernández-Caldas, Caraballo \& Lockey, 1991). De forma similar, niveles altos (88\%) de IgE anti- $B$. tropicalis fueron detectadas mediante ensayo ELISA, en una población pediátrica con asma bronquial de la ciudad de Santa Marta (Mendoza, Ruiz, Lagares, Garavito \& Egea, 2011), confirmando la importancia epidemiológica del ácaro en esta región de Colombia.

Una de las principales estrategias para prevenir o disminuir las alergias respiratorias ocasionadas por ácaros del polvo doméstico, es reducir su densidad en ambientes intramuros (Arlian \& Platts-Mills, 2001). Existen métodos para monitorear y controlar las poblaciones de ácaros, que en algunos casos requieren ser puras para su desarrollo y/o evaluación de su eficacia y eficiencia. Una de las formas más eficientes para masificar la producción de una especie pura de ácaro es su cultivo en condiciones controladas de laboratorio. Los cultivos puros de $B$. tropicalis pueden tener diferentes aplicaciones, como su utilización en la evaluación de la actividad acaricida de diferentes sustancias (Cuca, Mendoza-Mena, ÁlvarezCaballero, Macías-Villamizar \& Coy-Barrera, 2012; Insung,
Pumnuan, Mahakittikun \& Wangapai, 2016), producción de extractos alergénicos (Yi, Chew, Jiménez, Chua \& Lee, 1999; Fernández-Caldas, 2013), anticuerpos (Labrada et al., 2002; Yang et al., 2003), purificación de alérgenos específicos (Cardona, Eraso, Serna, Guisantes \& Martínez, 2004) y desarrollo de pruebas diagnósticas o para el monitoreo de los alérgenos a nivel ambiental (Tsay, Williams, Mitchell \& Chapman, 2002). El objetivo de este estudio fue evaluar las propiedades inmunoquímicas de extractos alergénicos de $B$. tropicalis obtenidos a partir de cultivos puros del ácaro.

\section{Materiales y métodos Cultivos de $B$. tropicalis}

Se tomaron muestras de polvo de colchón, de pacientes asmáticos de la ciudad de Barranquilla (Colombia), siguiendo el protocolo descrito por la EPA 747-R-95-007 Environmental Protection Agency (EPA 1995). Los ácaros aislados del polvo se cultivaron en medio nutritivo Tetramin estéril (Tetra, Blacksburg, VA, USA), en cajas de petri de $100 \times 15 \mathrm{~mm}$, siguiendo el protocolo previamente descrito por Yi, Chew, Jiménez, Chua \& Lee, 1999. Las condiciones del cultivo fueron: $74 \%$ de humedad relativa, $26,5^{\circ} \mathrm{C}( \pm 1,04)$ y en oscuridad. Después de dos semanas, los ácaros de la especie se identificaron con claves taxonómicas de acuerdo con Collof, 2009. Un número aproximado de 100 individuos fueron sub-cultivados en matraces de Erlenmeyer de 500 $\mathrm{mL}$ con $300 \mathrm{~g}$ de medio nutritivo, sellados con un tapón de gasa estéril. El crecimiento y reproducción de los ácaros se monitoreó periódicamente, también se evaluó la presencia de contaminantes como hongos o ácaros de otras especies. Los cultivos contaminados fueron descartados inmediatamente. Los ácaros en cultivos con alta densidad poblacional fueron separados por el método Tullgren descrito por Yi, Chew, Jiménez, Chua \& Lee, 1999. Los ácaros libres de medio se pesaron y almacenaron a $-80^{\circ} \mathrm{C}$ en tubos cónicos de poliestireno de $50 \mathrm{~mL}$.

\section{Extractos}

Un gramo de ácaros libre de medio se sometió a desgrasado con éter dietílico (Merck-Emsure ${ }^{\circledR}$ ) en un extractor Soxhlet de $250 \mathrm{~mL}$. La muestra desgrasada se introdujo en una cámara de extracción de gases (Extractor C100x) para eliminar el exceso de solvente, luego se sometió a extracción con $\mathrm{NH}_{4} \mathrm{HCO}_{3} 0.1$ $\mathrm{M}$, durante $24 \mathrm{~h}$ a $4^{\circ} \mathrm{C}$ y agitación constante $(110 \mathrm{rpm})$. El extracto crudo obtenido se centrifugó a 4,000 rpm durante 30 minutos a $4^{\circ} \mathrm{C}$. El sobrenadante se dializó durante 16 horas a $4^{\circ} \mathrm{C}$, frente a agua MiliQ, en membranas con tamaño de exclusión de 3,500 Daltons (Spectrum Laboratories Inc.). Los extractos se liofilizaron durante 48 horas, en un equipo Labconco ${ }^{\circledR}$ (Freezone 1 Liter Benchtop Freeze dry system), luego se pesaron y se almacenaron a $-20^{\circ} \mathrm{C}$. El rendimiento de extracción se calculó usando la siguiente expresión:

Rendimiento $=(\mathrm{mg}$ de proteína total $/ \mathrm{mg}$ de ácaros $) \times 100$. 


\section{Cuantificación de proteínas}

La cantidad de proteína total en los extractos liofilizados fue determinada mediante el ensayo Bradford (Bradford, 1976) usando el estuche Quick Start ${ }^{\mathrm{TM}}$ Bradford Protein Assay (Bio Rad) siguiendo las recomendaciones del fabricante. La densidad óptica de cada reacción se midió en lector de placas BioTek ${ }^{\circledR}$ Instruments Inc., a longitud de onda de $595 \mathrm{~nm}$. Los datos obtenidos se analizaron con el software Gen 5TM Data Analysis. La concentración de proteínas se determinó extrapolando la densidad óptica en la curva estándar de $\gamma$-globulina (GGB) construida previamente. Todas las lecturas se realizaron por triplicado y los resultados se expresaron como el valor de la media \pm desviación estándar (DE) de la cantidad de proteína total por peso seco de extracto.

\section{SDS-PAGE}

La integridad de los extractos se determinó por electroforesis SDS-PAGE utilizando un equipo Mini Protean ${ }^{\circledR}$ III cell (Bio Rad) según lo descrito por Laemmli ,1970. Se prepararon geles de poliacrilamida al 17\% T (gel de resolución) y 4\% C (gel de apilamiento). La corrida electroforética se realizó a 100 voltios por 120 minutos en tampón de corrida 1x compuesto por Tris base $74 \mathrm{mM}$ - Glicina $0,5 \mathrm{M}$ - SDS 10\%. Los geles se tiñeron con solución de azul de coomassie $0.1 \% \mathrm{p} / \mathrm{v}$ y se decoloraron con solución de ácido acético $10 \% \mathrm{v} / \mathrm{v}$ - metanol 40\% v/v. Como material de referencia se usó un extracto de B. tropicalis donado por el Dr. Enrique Fernández-Caldas (Director científico de Inmunotek - España).

\section{Perfil enzimático}

La actividad enzimática de los extractos de B. tropicalis se evaluó con el estuche comercial Api ${ }^{\circledR}$ Zym (Biomérieux, France, Lyon). Brevemente, $65 \mu \mathrm{L}$ de cada extracto $(1 \mathrm{mg} / \mathrm{mL})$ se agregó a las 20 cúpulas de reacción del Api Zym, cada una las cuales contenían un sustrato para una hidrolasa distinta, incluyendo una cúpula sin sustrato que fue el control negativo de la prueba. La reacción se incubó por 5 horas a $37^{\circ} \mathrm{C}$, seguido se agregó a cada cúpula una gota de reactivo Zym A y otra de Zym B (reactivos incluidos en el estuche). La cantidad de sustrato hidrolizado en cada cúpula se expresó en nanomoles (nmol), previa clasificación y comparación de la intensidad de la coloración de cada reacción, con una carta estándar de lectura semicuantitativa incluida en el Api Zym. La interpretación de los resultados se realizó acorde a las especificaciones del fabricante, usando una escala de lectura de 0 a 5 , donde " 0 " representa 0 $\mathrm{nmol}$, " 1 " = $5 \mathrm{nmol}$, "2" = $10 \mathrm{nmol}$, "3" = $15 \mathrm{nmol}$, "4" = 20 nmol y " 5 " $\geq 40 \mathrm{nmol}$. Un extracto producido a partir del medio de cultivo sin ácaros fue utilizado como control externo para determinar su influencia en la actividad enzimática.

\section{Western blot}

La presencia de proteínas de unión a la inmunoglobulina $\operatorname{IgE}$ en los extractos, se realizó mediante Western blot. Las fracciones proteicas separadas por SDS-PAGE se transfirieron a membranas de nitrocelulosa (Trans Blot ${ }^{\circledR}$, Transfer Medium de Bio-Rad), en un equipo Mini Trans-Blot ${ }^{\circledR}$ cell (BioRad) por 3 horas en tampón Tris - Glicina pH 8,4 (Tris $25 \mathrm{mM}$, Glicina $190 \mathrm{mM}$, Metanol $20 \% \mathrm{v} / \mathrm{v}$ ). Las membranas se bloquearon en tampón TBS-BSA (TBS $50 \mathrm{mM}$, BSA 3\% $\mathrm{p} / \mathrm{v}$, Tween 20 al $0,05 \% \mathrm{v} / \mathrm{v}$ ) por 1 hora, se lavaron tres veces con tampón TBST (TBS $50 \mathrm{mM}$, Tween-20 al 0,1\% $\mathrm{v} / \mathrm{v})$, luego se incubaron por 18 horas a $4^{\circ} \mathrm{C}$ con un grupo de sueros de pacientes atópicos con hipersensibilidad a los ácaros del polvo (prueba ImmunoCAP de Phadia UniCAP System, Pharmacia Upjohn, Uppsala, Sweden, positiva para B. tropicalis) (Egea et al., 2016), previamente diluidos 1/5 en tampón TBS-BSA. El exceso de suero se lavó con TBST y las membranas se incubaron por 1 hora con un anticuerpo IgG anti-IgE humana conjugada a fosfatasa alcalina, diluido 1/1000 en tampón TBS-BSA. El conjugado no unido se lavó con TBST y la membrana se reveló con el sustrato líquido BCIP-NBT (Bio-Rad, Hercules, CA) disuelto en tampón de la fosfatasa alcalina $\left(\mathrm{NaCl} 9,9 \mathrm{mM}-\mathrm{MgCl}_{2} 0,5 \mathrm{mM}\right.$ - Tris $\mathrm{HCl}$ 7,6 mM pH: 9,5).

\section{Análisis de datos}

Los resultados se expresaron como valores de la media y desviación estándar (DE) de tres réplicas independientes. Se realizó un análisis de varianza (ANOVA) con un nivel de confianza del $95 \%$, para establecer la variación del método de extracción de proteínas. Un valor $\mathrm{p}<0,05$ fue considerado estadísticamente significativo. Todas las pruebas estadísticas se realizaron con el Software de acceso libre "R" (www.rproject.org).

\section{Consideraciones éticas}

El estudio se realizó teniendo en cuenta, además de las disposiciones determinadas en la Ley 84 de 1989, los lineamientos consignados en la resolución $\mathrm{N}^{\mathrm{o}} 008430$ de 1993 expedida por el Ministerio de Salud de Colombia, por el cual se establecen las normas científicas, técnicas y administrativas para la investigación en salud. Se obtuvo consentimiento informado de los padres $\mathrm{y} / \mathrm{o}$ pacientes que suministraron muestras de sueros empleados en los ensayos.

\section{Resultados \\ Cultivos de B. tropicalis}

Los cultivos puros mostraron máximo crecimiento entre la cuarta y quinta semana de iniciación del cultivo, observándose individuos de ambos sexos, huevos y estados larvales (Figura 1). En la quinta semana, la producción promedio de ácaros fue de $0,9 \mathrm{~g} / 300 \mathrm{~g}$ de medio. Después de la quinta semana se detectó un alto número de ácaros muertos en el tapón de gasa de los matraces, lo que sugiere agotamiento del medio de crecimiento. Para los experimentos de extracción se utilizaron cultivos con cinco semanas de crecimiento. 


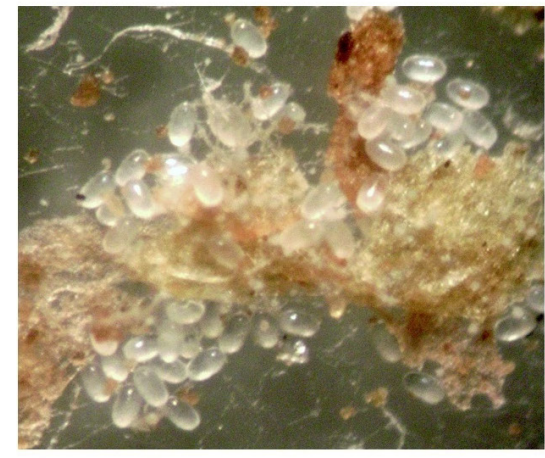

a)

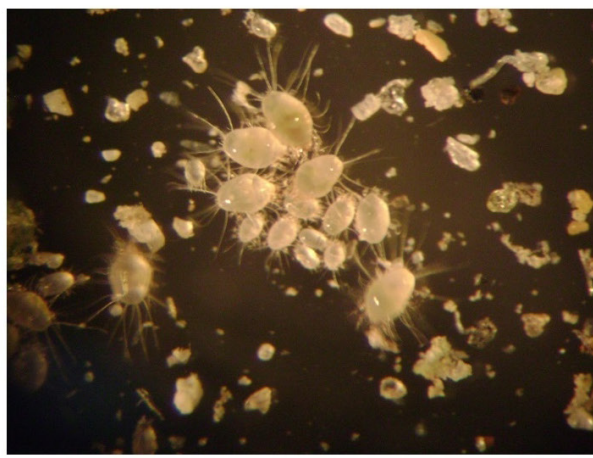

b)

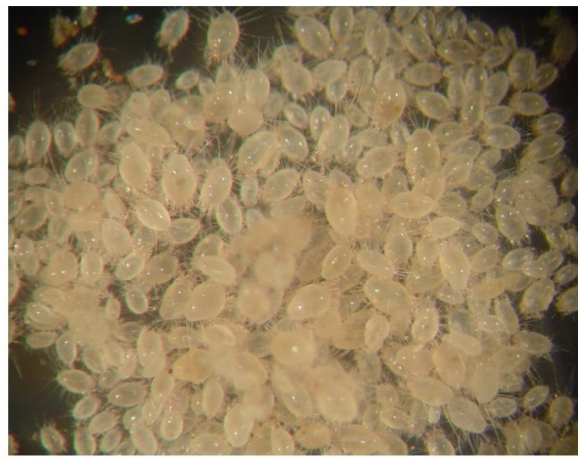

c)

Figura 1. Estadios de vida de B. tropicalis en el cultivo in vitro. a) Alta proliferación de huevos después de la segunda semana, b) ninfas y adultos jóvenes entre la tercera y cuarta semana, c) Población de ácaros adultos en la quinta semana.

\section{Extractos}

La Tabla I muestra los resultados de la extracción de proteína desde los extractos de $B$. tropicalis, a partir de cuatro cultivos independientes (codificados como A, B, C y D). La cantidad de material seco obtenido después de la extracción de proteínas estuvo entre $30,56-40,2 \mathrm{mg}(35,8 \pm 4,04)$; el rendimiento de la extracción fue de 3,61\% $( \pm 0,42)$. La concentración promedio de proteína total cuantificada por el método de Bradford fue de $190,9 \mu \mathrm{g} / \mathrm{mg}( \pm 13,64)$ de extracto liofilizado. El análisis de varianza mostró diferencia no significativa entre la concentración de proteína obtenida en los cuatro extractos alergénicos (valor $\mathrm{F}=0,927$; valor $p=0,505$ ).

\section{SDS-PAGE}

El análisis electroforético de los extractos mostró presencia de bandas con tamaños entre 21 y $200 \mathrm{kDa}$. Los extractos obtenidos a partir de los cultivos A y B mostraron bandas más nítidas y un patrón de proteínas similar al observado en el extracto de referencia de $B$. tropicalis (Inmunotek) (Figura 2).

\section{Perfil enzimático}

La Tabla II presenta los resultados de la actividad enzimática de los extractos de B. tropicalis frente a 19 hidrolasas, evaluada por el método semicuantitativo del Api ${ }^{\circledR}$ Zym. A la concentración de $1 \mathrm{mg} / \mathrm{mL}$, todos los extractos mostraron actividad hidrolasa hacia la mayoría de los sustratos evaluados, mientras que el extracto de medio cultivo libre de ácaros no presentó actividad, por lo que se descarta su influencia en los extractos de ácaros producidos. Al comparar con el extracto de referencia de $B$. tropicalis se encontró que actividades valina arilamidasa y $\alpha$-quimotripsina eran más bajas en los extractos preparados en el laboratorio; en contraste, actividad esterasa $\mathrm{C} 4$ no fue detectada en el extracto de referencia, pero estuvo presente en todos los extractos preparados.

\section{Western blot}

Este ensayo demostró que los extractos obtenidos desde los cultivos $\mathrm{B}, \mathrm{C}$ y $\mathrm{D}$, presentaron un perfil de proteínas de unión a IgE sérica muy similar al observado en el extracto comercial. El grupo de sueros utilizados en este ensayo reconoció bandas

Tabla I. Rendimiento de la extracción de proteínas de B. tropicalis cultivados in vitro. a) La concentración de proteína se expresa en $\mu \mathrm{g}$ de proteína total/ $\mathrm{mg}$ de extracto liofilizado. b) Valores de la media de dos determinaciones independientes.

\begin{tabular}{|c|c|c|c|c|}
\hline Cultivo & $\begin{array}{c}\text { Peso de ácaros } \\
(\mathbf{m g})\end{array}$ & $\begin{array}{c}\text { Peso de extracto } \\
\text { seco }(\mathbf{m g})\end{array}$ & $\begin{array}{c}\text { Rendimiento de } \\
\text { extracción }(\mathbf{p} \%)\end{array}$ & $\begin{array}{c}\text { [Proténa] } \\
(\boldsymbol{\mu g} / \mathbf{m g})^{\mathbf{a}}\end{array}$ \\
\hline $\mathrm{A}$ & 1000 & 40.2 & 4.02 & 202.04 \\
\hline $\mathrm{B}$ & 1090 & 37.1 & 3.40 & 201.4 \\
\hline $\mathrm{C}$ & 980 & 30.56 & 3.12 & 186.75 \\
\hline $\mathrm{D}$ & 900 & 35.2 & 3.91 & 173.38 \\
\hline $\mathrm{Media}^{\mathrm{b}}$ & 992.5 & 35.8 & 3.61 & 190.9 \\
\hline $\mathrm{DE} \pm$ & 78.05 & 4.04 & 0.42 & 13.64 \\
\hline
\end{tabular}




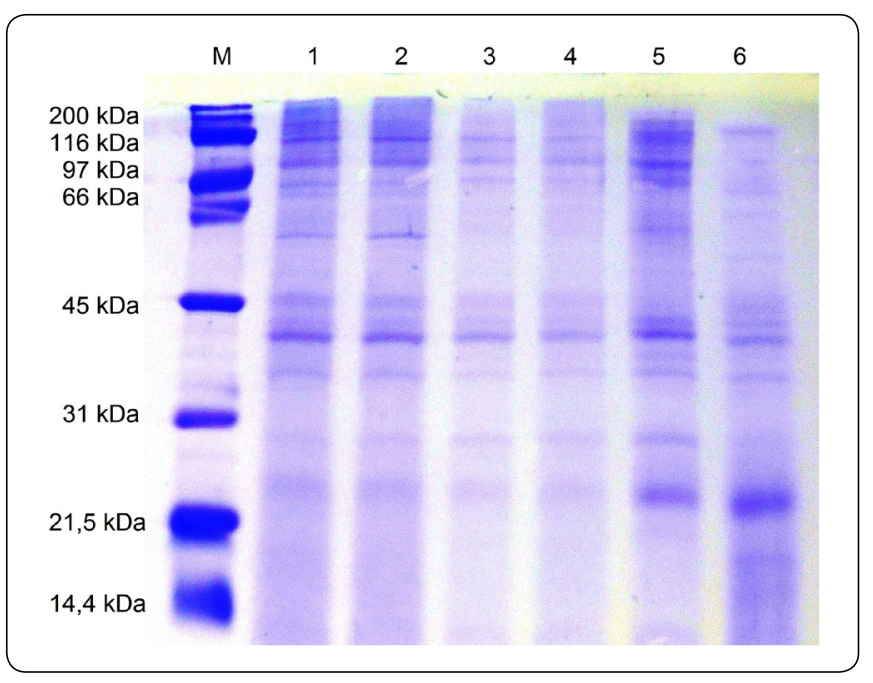

Figura 2. Perfil electroforético de los extractos proteicos de B. tropicalis. M: Marcador de Peso molecular. Precision Plus Protein ${ }^{\mathrm{TM}}$ Unstained Standards - BioRad. Carril 1: Cultivo A, Carril 2: Cultivo B, Carril 3: Cultivo C, Carril 4: Cultivo D, Carril 5: Extracto comercial.

con tamaño entre 15 y $150 \mathrm{kDa}$, destacándose una banda común cercana a $22 \mathrm{kDa}$ y un conjunto de bandas entre 30 y $75 \mathrm{kDa}$ (Figura 3).

\section{Discusión}

Se logró establecer un cultivo puro y la producción de extractos con actividad alergénica y enzimática hidrolasa del ácaro $B$. tropicalis. Durante la etapa de cultivo se observó que los ácaros mantenidos bajo condiciones controladas de humedad relativa $(74 \%)$ y temperatura $\left(26,5^{\circ} \mathrm{C}\right)$, logran desarrollarse completamente desde huevo hasta adultos en 37 días (aprox. 5 semanas). Este resultado difiere de lo descrito por Mariana, Ho \& Heah, 1996 quienes reportaron que el ciclo de vida de $B$. tropicalis es más corto $(22,9 \pm 6,4$ días $)$ en condiciones de temperatura de $25^{\circ} \mathrm{C}$ y humedad relativa de $75 \%$. Esta diferencia puede atribuirse a factores como: las cepas de $B$. tropicalis usada para iniciar los cultivos, el medio nutritivo y otras condiciones ambientales fluctuantes en condiciones no controladas.

Estudios previos describen que la humedad relativa es uno de los factores más relevantes en el crecimiento y desarrollo de los ácaros del polvo doméstico (Hart, 1998). También se ha demostrado que la clase y composición del medio de cultivo influye en la fisiología digestiva y el metabolismo de los ácaros (Vidal-Quist et al., 2017). En nuestro estudio se utilizó Tetramin como medio de cultivo, éste presenta un alto contenido de vitaminas, minerales, proteínas y ácidos grasos, constituyendo un suplemento favorable para el crecimiento de las poblaciones de B. tropicalis. Tetramin fue reportado previamente en el cultivo de esta especie, a partir de ácaros colectados en Singapur (Yi, Chew, Jiménez, Chua \& Lee, 1999) y Malaysia (Hart, 1998);

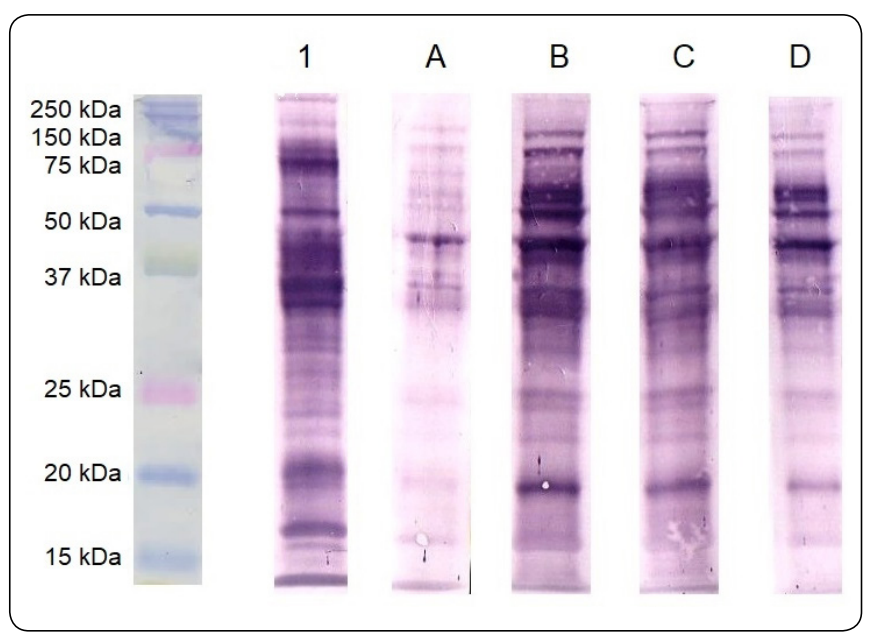

Figura 3. Resultados del Western blot de los extractos proteicos: comercial y producidos. 1: Extracto de comercial; A: Extracto A; B: Extracto B; C: Extracto C; D: Extracto D.

también fue usado en el cultivo de otros ácaros del polvo como Dermatophagoides farinae, D. pteronyssinnus, Aleuroglyphus ovatus y Glycycometus malaysiensis. (Tang, Wong, Mak \& Ho, 2011; Mendoza, Ruiz, Lagares, Garavito \& Egea, 2011; Ree, Lee, Kim, Jeon \& Hong, 1997).

Por otra parte, se ha descrito que la concentración de proteínas y la expresión de los alérgenos en cultivos in vitro de ácaros del polvo doméstico está influenciada por la fase del cultivo (Mendoza, Ruiz, Lagares, Garavito \& Egea, 2011), el desarrollo larval y las condiciones ambientales (Eraso et al., 1998; VidalQuist et al., 2015; Morales, Iraola, Leonor \& Carnés, 2013). En nuestro estudio los ácaros usados para la preparación de los extractos estuvieron en estadio adulto (5 semanas de cultivo), lográndose una producción de ácaros similar $(0,9 \mathrm{~g} / 300 \mathrm{~g}$ de medio) a la reportada en el estudio de Yi, Chew, Jiménez, Chua \& Lee, 1999 (entre 0,4 y 1,6 g/300 g de medio).

La caracterización bioquímica de los extractos mostró un perfil de bandas electroforéticas similar entre los extractos preparados y el extracto de referencia, detectándose bandas entre 21 a 200 $\mathrm{kDa}$. En este rango de tamaños se encuentran algunos alérgenos de $B$. tropicales reportados previamente, tales como: Blo t 1 $(25 \mathrm{kDa})$, Blo t $3(24 \mathrm{kDa})$, Blo t $4(55 \mathrm{kDa})$, Blo t $6(26 \mathrm{kDa})$, Blo t $10(33 \mathrm{kDa})$ y Blo t $11(102 \mathrm{kDa})$ (Chua et al., 2007); sin embargo, para confirmar su identidad se requiere de otras pruebas bioquímicas. Debido a que algunos de los alérgenos de B. tropicalis poseen actividad enzimática hidrolasa, se utilizó el ensayo de Api ${ }^{\circledR}$ Zym para detectarlas, encontrándose actividades asociadas a los alérgenos Blo $t 1$ (proteasa), Blo t 3 (tripsina) Blo t 4 (alfa- amilasa) y Blo t 6 (quimotripsina). La presencia de estas actividades en extractos de $B$. tropicalis fue reportada previamente por Montealegre, Quiñones, Torres \& Goth, 2002. 
Tabla II. Resultado de actividad enzimática evaluada con el estuche Api® Zym. La cantidad de sustrato hidrolizado fue determinada en nanomoles ( $\mathrm{nmol}$ ) y comparada con una carta estándar de lectura semicuantitativa. Su interpretación va en escala de 0 a 5 , donde " 0 " representa 0 nmol, " 1 " = 5 nmol, " 2 " = $10 \mathrm{nmol}$, " 3 " = $15 \mathrm{nmol}$, " 4 " = $20 \mathrm{nmol}$ y " 5 " $\geq 40 \mathrm{nmol}$. Observe que el medio de cultivo libre de ácaros no presentó actividad hidrolasa.

\begin{tabular}{|c|c|c|c|c|c|c|c|c|}
\hline \multirow[b]{2}{*}{$\mathbf{N}^{\circ}$} & \multirow{2}{*}{$\begin{array}{l}\text { Tipo de } \\
\text { Enzima }\end{array}$} & \multirow[b]{2}{*}{ Enzima } & \multicolumn{6}{|c|}{ Actividad Enzimática } \\
\hline & & & $\mathbf{A}$ & B & $\mathbf{C}$ & D & Comercial & $\begin{array}{l}\text { Medio } \\
\text { Cultivo }\end{array}$ \\
\hline 1 & Control & & 0 & 0 & 0 & 0 & 0 & 0 \\
\hline 2 & Fosfatasa & Fosfatasa alcalina & 4 & 2 & 2 & 1 & 4 & 0 \\
\hline 3 & Lipasa & Esterasa C4 & 3 & 3 & 3 & 3 & 0 & 0 \\
\hline 4 & Lipasa & Esterasa Lipasa C8 & 3 & 3 & 3 & 3 & 2 & 0 \\
\hline 5 & Lipasa & Lipasa C14 & 0 & 0 & 0 & 1 & 0 & 0 \\
\hline 6 & Proteasa & Leucina arilamidasa & 5 & 4 & 4 & 3 & 5 & 0 \\
\hline 7 & Proteasa & Valina arilamidasa & 1 & 1 & 1 & 2 & 4 & 0 \\
\hline 8 & Proteasa & Cisteina arilamidasa & 1 & 0 & 0 & 1 & 2 & 0 \\
\hline 9 & Proteasa & Tripsina & 5 & 4 & 4 & 4 & 5 & 0 \\
\hline 10 & Proteasa & $\alpha$-quimiotripsina & 2 & 2 & 2 & 2 & 4 & 0 \\
\hline 11 & Fosfatasa & Fosfatasa ácida & 5 & 4 & 4 & 4 & 5 & 0 \\
\hline 12 & Fosfatasa & Naftol-AS-BI-fosfohidrolasa & 4 & 4 & 4 & 4 & 5 & 0 \\
\hline 13 & Glicosidasa & $\alpha$-galactosidasa & 4 & 4 & 4 & 4 & 4 & 0 \\
\hline 14 & Glicosidasa & $\beta$-galactosidasa & 5 & 5 & 5 & 5 & 5 & 0 \\
\hline 15 & Glicosidasa & $\beta$-glucuronidasa & 4 & 4 & 4 & 4 & 5 & 0 \\
\hline 16 & Glicosidasa & $\alpha$-glucosidasa & 3 & 3 & 3 & 3 & 3 & 0 \\
\hline 17 & Glicosidasa & $\beta$-glucosidasa & 3 & 3 & 4 & 3 & 3 & 0 \\
\hline 18 & Glicosidasa & $\mathrm{N}$-acetil- $\beta$-glucosaminidasa & 4 & 4 & 4 & 4 & 5 & 0 \\
\hline 19 & Glicosidasa & $\alpha$-mannosidasa & 4 & 4 & 4 & 3 & 3 & 0 \\
\hline 20 & Glicosidasa & $\alpha$-fucosidasa & 2 & 3 & 2 & 3 & 5 & 0 \\
\hline
\end{tabular}

Por otra parte, estudios publicados por Morales, Iraola, Leonor \& Carnés, 2013; Morgan \& Arlian, 2006 y Cardona, Guisantes, Eraso, Serna \& Martínez, 2006, reportan actividades enzimáticas hidrolasas similares a las encontradas en el presente estudio, sugiriendo la existencia de un perfil enzimático común para ácaros de almacenamiento, incluyendo B. tropicalis.

En cuanto al carácter alergénico, el ensayo de Western blot, usando sueros sanguíneos de individuos con hipersensibilidad alérgica a los ácaros, demostró que los extractos contienen proteínas de unión a IgE, por lo que podrían ser utilizados en pruebas de inmunodetección in vitro (por ejemplo, en ensayos por inmunoabsorción ligado a enzimas o ELISA) o in vivo (por ejemplo, en pruebas cutáneas como el prick test). Debido a que $B$. tropicalis es una de las más importantes fuentes de alérgenos intradomiciliarios en el Caribe Colombiano, con sensibilidades mayores al $80 \%$ en la población asmática (Mendoza \& Lozano, 2011; Puerta, Fernández-Caldas, Lockey \& Caraballo, 1993), es de gran relevancia contar con cultivos y extractos alergénicos que puedan usarse en el diagnóstico de la sensibilidad alérgica y en las pruebas de detección de contaminación ambiental por alérgenos.

\section{CONCLUSIONES}

En conclusión presentamos un método para el desarrollo de cultivos in vitro y extractos alergénicos del ácaro del polvo B. tropicalis, que puedan ser empleados como herramientas para el desarrollo de productos tecnológicos destinados al diagnóstico clínico o a la detección de alérgenos en espacios intramuros. No obstante, los resultados presentados 
aquí comprenden solo una caracterización preliminar de los extractos, requiriéndose estudios posteriores para la estandarización biológica de los mismos que permitan su uso seguro en ensayos clínicos.

\section{Conflicto de InTEReses}

Los autores declaran no tener conflicto de interés

\section{AgradeCIMIENTOS}

Esta investigación se realizó en el marco del proyecto "Validación de dos métodos inmunoquímicos para la detección de alérgenos de ácaros intradomiciliarios en espacios intramuros usando anticuerpos IgY en tres ciudades colombianas" grant: 10012010 financiado por la Universidad del Norte y la Dirección de Investigación, Desarrollo e Innovación (DIDI).

\section{Referencias}

Acuña-Cantillo, L., Moreno, A.S., Garavito, G., Egea, E., \& MendozaMeza, D.L. (2015). Prevalencia y densidad de ácaros domésticos en comunidades marginadas de dos ciudades de Colombia. Revista Cubana de Investigaciones Biomédicas, 34(1),18-26. http://www.bvs.sld.cu/revistas/ibi/vol34_1_15/ ibi02115.htm

Arlian, L.G. \& Platts-Mills, T.A. (2001). The biology of dust mites and the remediation of mite allergens in allergic disease. Journal Allergy Clinical Immunology, 107(3 Suppl.), S406-413. http:// dx.doi.org/10.1067/mai.2001.113670

Bradford, M.M.(1976). Arapid and sensitive method for the quantitation of microgram quantities of protein utilizing the principle of protein-dye binding. Analytical Biochemistry, 72(1-2), 248254. https://doi.org/10.1016/0003-2697(76)90527-3

Caraballo, L. (1999). Caracterización inmunoquímica y molecular de los alérgenos de Blomia tropicalis, un ácaro causante de asma en el trópico. Revista de la Academia Colombiana de Ciencias Exactas, Físicas y Naturales, 23(88), 433-443. http://www. accefyn.org.co/revista/Vol_23/88/433-443.pdf

Cardona, G., Eraso, E., Serna, L.A., Guisantes, J.A. \& Martínez, J. (2004). Analysis of the allergen expression of Blomia tropicalis and Blomia kulagini (Astigmata: Glycyphagidae) cultures. Journal of Medical Entomology, 41(6),1068-1072. http:// dx.doi.org/10.1603/0022-2585-41.6.1068

Cardona, G., Guisantes, J., Eraso, E., Serna, L.A. \& Martínez, J. (2006). Enzymatic analysis of Blomia tropicalis and Blomia kulagini (Acari: Echimyopodidae) allergenic extracts obtained from different phases of culture growth. Experimental and Applied Acarology, 39(34), 281-288. DOI:10.1007/s10493-006-9009-2

Chua, K.Y., Cheong, N., Kuo, I.C., Lee, B.W., Yi, F.C., Huang, C.H. \& Liew, L.N. (2007). The Blomia tropicalis allergens. Protein \& Peptide Letters, 14(4), 325-333. DOI: $10.2174 / 092986607780363862$

Collof, M. (2009) Dustmites. Collingwood,Australia. Csiro Publishing. DOI: 10.1007/978-90-481-2224-0

Cuca, L.E., Mendoza-Meza, D.L., Álvarez-Caballero, J.M., Macías-Villamizar, V.E. \& Coy-Barrera, E.D. (2012). Actividad acaricida de extractos de lauráceas sobre los ácaros intradomiciliarios Dermatophagoides farinae y Blomia tropicalis. Revista Cubana de Plantas Medicinales,
17(4), 308-319. http://bvs.sld.cu/revistas/pla/vol17_4_12/ pla03412.htm

Egea, E., Garavito, G., Fang, L., Mendoza, D., Escamilla, J.M., De Los Ríos, E., Dennis, R., \& Sánchez-Borges, M. (2016). Influencia de los niveles séricos de vitamina D sobre la respuesta IgE en niños escolares con asma en comunidades pobres. Revista Alergia México, 63(3), 252-269. http://dx.doi.org/10.29262/ ram.v63i3.183

Environmental Protection Agency. U.S. September 1995. [Access: 1204-2017]. Sampling House Dust for Lead: Basic Concepts and Literature Review, Final Report, EPA 747-R-95-007: https:// www.epa.gov/sites/production/files/documents/r95-007.pdf

Eraso, E., Martínez, J., García-Ortega, P., Martínez, A., Palacios, R., Cisterna, R., \& Guisantes, J.A. (1998). Influence of mite growth culture phases on the biological standardization of allergenic extracts. The Journal of Investigational Allergology and Clinical Immunology, 8(4), 201-206. https://www.ncbi. nlm.nih.gov/pubmed/9777533

Fernández-Caldas, E. (2013). Towards a more complete standardization of mite allergen extracts. International Archives of Allergy and Immunology, 160(1), 1-3. https://doi.org/10.1159/000341271

Fernández-Caldas, E., Puerta, L., Mercado, D., Lockey, R.F. \& Caraballo, L., (1993). Mite fauna, Derp I, Derf I and Blomia tropicalis allergen levels in a tropical city. Clinical \& Experimental Allergy, 23(4), 292-297. DOI: 10.1111/j.13652222.1993.tb00325.x

Hart, B.J. (1998). Life cycle and reproduction of house-dust mites: environmental factors influencing mite populations. Allergy, 53(48 Suppl.),13-17. DOI:10.1111/j.1398-9995.1998. tb04990.x

Insung, A., Pumnuan, J., Mahakittikun, V. \& Wangapai, T. (2016). Effectiveness of essential oils of medicinal plants at reducing the amounts of allergen produced by the European house dust mite Dermatophagoides pteronyssinus (Trouessart). Journal of the Acarological Society of Japan, 25 (S1), 179-184. http:// doi.org/10.2300/acari.25.Suppl_179

Labrada, M., Uyema, K., Sewer, M., Labrada, A., González, M., Caraballo, L. \& Puerta, L. (2002). Monoclonal antibodies against Blot 13, a recombinant allergen from Blomia tropicalis. International Archives of Allergy and Immunology, 129(3), 212-218. https://doi.org/10.1159/000066775

Laemmli, U.K. (1970). Cleavage of structural proteins during the assembly of the head of bacteriophage T4. Nature, 227(5259), 680-685. DOI:10.1038/227680a0.

Mariana, A., Ho, T.M., \& Heah, S.K. (1996). Life-cycle, longevity and fecundity of Blomia tropicalis (Acari: Glycyphagidae) in a tropical laboratory. The Southeast Asian Journal of Tropical Medicine and Public Health, 27(2), 392-395. http://www. tm.mahidol.ac.th/seameo/1996-27-2/1996-27-2-392.pdf

Mendoza, D.L, \& Lozano, S. (2011). Respuesta IgE específica anti Blomia tropicalis en niños asmáticos residentes en Santa Marta, una ciudad del caribe Colombiano. Duazary, 8(1), 9-16.http:// dx.doi.org/10.21676/2389783X.246

Mendoza, D.L., Ruiz, T., Lagares, A., Garavito, G., \& Egea, E. (2011). Caracterización de la actividad alergénica y enzimática de extractos somáticos producidos a partir de cultivos in vitro del ácaro Dermatophagoides farinae. Salud Uninorte, 27(1), 11-21. http://rcientificas.uninorte.edu.co/index.php/salud/ article/view/1881/2138 
Mercado, D., Puerta, L. \& Caraballo, L. (1996). Niveles de alérgenos de ácaros en el polvo de habitación en Cartagena, Colombia. Biomédica, 16(4), 307-314. http://dx.doi.org/10.7705/ biomedica.v16i4.921

Meza, J., Mendoza, D.L. \& Mercado, D. (2008). Identificación de ácaros del polvo casero en colchones y almohadas de niños alérgicos de Santa Marta, Colombia. Duazary, 5(1), 24-31. http://dx.doi.org/10.21676/2389783X.555

Montealegre, F., Quiñones, C., Torres, N.\& Goth, K. (2002). Detection of serine proteases in extracts of the domestic mite Blomia tropicalis. Experimental and Applied Acarology, 26(1-2), 87-100. DOI: 10.1023/A:1020931221953

Morales, M., Iraola, V., Leonor, J.R. \& Carnés, J. (2013). Enzymatic activity of allergenic house dust and storage mite extracts. Journal of Medical Entomology, 50(1), 147-154. http://dx.doi. org/10.1603/ME12154

Morgan, M.S, \& Arlian, L.G. (2006). Enzymatic activity in extracts of allergy-causing astigmatid mites. Journal of Medical Entomology, 43(6), 1200-1207. http://dx.doi. org/10.1603/0022-2585(2006)43[1200:EAIEOA]2.0.CO;2

Puerta, L., Fernández-Caldas, E., Caraballo, L. \& Lockey, R.F. (1991). Sensitization to Blomia tropicalis and Lepidoglyphus destructor in Dermatophagoides spp-allergic individuals. Journal of Allergy and Clinical Immunology, 88(6), 943-950. https://doi. org/10.1016/0091-6749(91)90252-J

Puerta, L., Fernández-Caldas, E., Lockey, R. \& Caraballo, L. (1993) Mite allergy in the tropics: sensitization to six domestic mites species in Cartagena, Colombia. Journal of Investigational Allergology and Clinical Immunology, 3(4), 198-204. https:// www.ncbi.nlm.nih.gov/pubmed/8281353

Ree, H., Lee, I.Y., Kim, T.E., Jeon, S.H., \& Hong, C.S. (1997). Mass culture of house dust mites Dermatophagoides farinae and D. pteronyssinus (Acari: Pyroglyphidae). Medical and Entomology Zoology, 48(2), 109-116. http://doi.org/10.7601/ mez.48.109

Tang, J.C., Wong, S.F., Mak, J.W. \& Ho, T.M. (2011). Antigenic profile of Blomia tropicalis, Aleuroglyphus ovatus and Glycycometus malaysiensis. Tropical Biomedicine, 28(2), 223-236. http:// www.msptm.org/files/223_-_236_Wong_SF.pdf

Tsay, A., Williams, L., Mitchell, E.B. \& Chapman, M.D. (2002). A rapid test for detection of mite allergens in homes. Clinical and Experimental Allergy, 32(11), 1596-1601. doi:10.1046/j.13652222.2002.01533.x

Vidal-Quist, J.C., Ortego, F., Lombardero, M., Castañera, P., \& Hernández-Crespo, P. (2015). Allergen expression in the European house dust mite Dermatophagoides pteronyssinus throughout development and response to environmental conditions. Medical and Veterinary Entomology, 29(2), 137146. DOI: $10.1111 / \mathrm{mve} .12102$

Vidal-Quist, J.C., Ortego, F., Rombauts, S., Castañera, P. \& HernándezCrespo, P. (2017). Dietary shifts have consequences for the repertoire of allergens produced by the European house dust mite. Medical and Veterinary Entomology, 31(3):272-280. DOI:10.1111/mve.12234.

Yang, L., Cheong, N., Wang, D.Y., Lee, B.W., Kuo, I.C., Huang, C.H. \& Chua, K.Y. (2003). Generation of monoclonal antibodies against Blo t 3 using DNA immunization with in vivo electroporation. Clinical and Experimental Allergy, 33(5), 663-668. DOI:10.1046/j.1365-2222.2003.01648.x

Yi, F.C., Chew, F.T., Jiménez, S., Chua, K.Y., \& Lee, B.W. (1999). Culture of Blomia tropicalis and IgE immunoblot characterization of its allergenicity. Asian Pacific Journal of Allergy and Immunology, 17(3), 189-194. https://search. proquest.com/docview/1031014495?pq-origsite $=$ gscholar 